\title{
Brain Fag Syndrome - a myth or a reality
}

\section{BA Ola1', O Morakinyo², AO Adewuya'}

${ }^{1}$ Department of Psychiatry, Lagos State University College of Medicine,Ikeja. Lagos, Nigeria

2Department of Psychiatry, College of Health Sciences, University of Benin, Benin

\begin{abstract}
The Brain Fag Syndrome (BFS) is defined in the Diagnostic and Statistical Manual of Mental Disorders (DSM-IV) as a culture bound syndrome. BFS is a tetrad of somatic complaints; cognitive impairments; sleep related complaints; and other somatic impairments. Prince first described this psychiatric illness associated with study among African students in 1960. There have been questions relating to the nosological status of the syndrome as to whether: BFS is an objective or subjective phenomenon; it is one phenomenon or a variant of other known disorders; it is a mental illness ? These three questions pose challenges to the culture bound/depressive or anxiety equivalent approach to the condition. The scope of this paper is the scope of BFS history from its first reference in the psychological medicine to the most contemporary descriptions in transcultural psychiatry. The conceptual history of BFS is divided into four major perspectives: Traditional medicine, Psychoanalysis, Biopsychological and Transcultural psychiatry. This helps to outline some of the key issues, helps to clarify its nosological status, its present status and helps to set the stage for the future progress. From its conceptual history, BFS as a phenomenon, with its distinct presentations, is subjectively real and is best classified with the framework of psychiatry, psychology and or sociology. The existence of BFS is evidenced by case as well as epidemiological reports of the condition in different locations. However, its course, response to treatment and outcome deserve more attention than has been given.
\end{abstract}

Keywords: Brain-fag; Africa; Culture; Psychiatry

Received: $20-04-2008$

Accepted: $10-06-2008$

\section{Introduction}

The Brain Fag Syndrome (BFS) was defined in the Diagnostic and Statistical Manual of Mental Disorders (DSM-IV) as a culture bound syndrome in 1994, just like Koro syndrome and other culture related syndromes. ${ }^{1}$ BFS is a tetrad of somatic complaints; cognitive impairments; sleep related complaints; and other somatic impairments. The somatic complaints consist of pains and burning sensations around the head and neck; the cognitive impairments consist of inability to grasp the meaning of written and sometimes spoken words, and inability to concentrate as well as inability to concentrate and poor retention; sleep related complaints consisting of fatigue and sleepiness in spite of adequate rest; and other somatic impairments such as blurring, eye pain and excessive tearing. The diagnosis of BFS rests not only on the presence of symptoms but also on the association between (a) the unpleasant sensations around the head/neck and

Correspondence:

Dr BA Ola

Department of Psychiatry, Lagos State University College of Medicine,

Ikeja. Lagos

email:wobola@yahoo.com (b) study difficulty. These two factors (a and b) are necessary for determining the caseness of BFS and represent the construct of the syndrome.

Prince first described this psychiatric illness associated with study among African students in 1960. ${ }^{2}$ He called this illness the Brain Fag Syndrome (BFS), the phrase "brain fag" being the name by which the students themselves called the condition, which they believed was due to brain fatigue.

The historical ideas about this illness are not only organised by dates, places or people, but by major perspectives that have attempted to explain the condition through the ages. The earlier reference to this study-related condition from the traditional perspective has not been recorded in literature. However, it appeared in the Western literature in the sixties and perspectives from psychoanalysis, psychiatry and psychology have since attempted to explain it. Emerging from this conceptual history are 3 questions - all of which concern the BFS nosology, that is, how it should be best classified.

One question asks: "is BFS an objective or subjective phenomenon?" Another asks: "is it one phenomenon or a variant of other known ones?" The third asks: "is it a mental illness?" These three questions pose challenges to the culture bound/depressive or anxiety equivalent approach to the 
condition. The conceptual history helps to outline some of the key issues, helps to clarify its nosological status, its present status and helps to set the stage for the future progress. Hence this conceptual history is an important tool for the study of BFS and of psychiatric conditions at large.

\section{Protoype case: BFS in Nigeria ${ }^{2}$}

Prince describes a Yoruba male in his late 20, who when studying for an exam began to have sharp pains in the head and could not grasp what he was reading. He slept more than usual, and had difficulty in forcing himself to go to school in the morning. When writing the examinations, he felt that he knew the answers, but was unable to recall them; his mind was blank. His right hand was weak and shook so that he couldn't write. Because of these symptoms, he was forced to postpone writing the examinations for several years. His symptoms improved greatly with Largactil and reassurance. ${ }^{2}$

\section{Epidemiology}

\section{Geographical distribution of BFS}

Prince first described BFS in 1960. ${ }^{2}$ Records of BFS in Nigerian folklore has not been investigated as diligent search of literature, electronic, manual, and personal communication, did not reveal any work on the history of this illness among traditional healers. There is a dearth of studies on how symptoms are labelled and interpreted particularly in Nigerian cultures where BFS was first discovered and tends to occur. After the report by Prince ${ }^{2}$, BFS has been reported elsewhere in Africans in Liberia, Uganda, Ivory Coast and South Africa but it is rather rare among Caucasians as shown in Tables I to III. 3,4,5,6,7 It has also been reported in races other than blacks such as among Brazilians; male seminary students in Argentina; Indians, Siamese, Malayan and Chinese students; as well as blacks outside of Africa i.e. among the Ethiopian Jew., 8,9 Similarity in cultural expression of idioms of distress might explain this finding; hence BFS is a culture related disorder. However, many of these reports on BFS in other races than blacks were via personal communication to Prince and also via missionary records. Very few were case illustrations and these were just about brain fag symptoms and not BFS per se. Studies using BFS specific instruments are needed to address this issue.

\section{Prevalence rates of Brain fag symptoms or syndrome}

Epidemiologic studies of BFS have been few as revealed in Tables I to III. The prevalence rate of brain fag ranges from 6 to $53.8 \%$. This wide range could result from the fact that these studies addressed different outcome measures and used different instruments to assess brain fag. The majority of the studies (six out of ten) reported rates of the brain fag symptoms rather than brain fag syndrome. Prevalence rates of BFS had been reported in a few studies following the description by Prince., 2,10,11,12,13 These studies had all been conducted in Nigeria and all used BFSS or its modified version. Fatoye and Morakinyo in 2003 found a rate of 22.9\% among secondary school students, Morakinyo and Peltzer in 2002 , found a rate of $13.7 \%$ among apprentices, Fatoye found a rate of 38.9\% among university students, and Ola found a rate of $40.2 \%$ among senior secondary school students. $7,11,12,13$ Comparison between these studies is difficult because of the differential sample characteristics. While it cannot be ascertained

\section{Table I: Review of BFS Literature between 1960 and 1979}

\begin{tabular}{|c|c|c|c|c|c|}
\hline Author (year) & Location & Type of study & Outcome measure & Main Outcome & Methodological problem \\
\hline Prince (1960) & Nigeria & Clinical & Interview & $\mathrm{BFS}$ & Selection bias \\
\hline Prince (1962) & Nigeria & Survey & $\begin{array}{l}\text { Short Self-report } \\
\text { questionnaire }\end{array}$ & $\mathrm{BFS}$ & $\begin{array}{l}\text { Validity instrument } \\
\text { Sample mostly males }\end{array}$ \\
\hline Boroffka and Marinho (1963) & Nigeria & Clinical & Interview & BF symptoms & Selection bias \\
\hline Neki and Marinho (1968) & Nigeria & Clinical & $\begin{array}{l}\text { Interview and trial of } \\
\text { antidepressant }\end{array}$ & BFS as Depressive variant & $\begin{array}{l}\text { Selection bias } \\
\text { Observer bias }\end{array}$ \\
\hline German and Arya (1969) & Uganda & Clinical & Interview & BF symptoms & $\begin{array}{l}\text { Sampling technique } \\
\text { First year university students }\end{array}$ \\
\hline Wintrop (1970) & Liberia & Clinical & Questionnaire & BF symptoms & $\begin{array}{l}\text { No exclusion Criteria } \\
\text { First year university students }\end{array}$ \\
\hline German and Assael (1971) & Uganda & Clinical & Interview & BF symptoms & $\begin{array}{l}\text { Unclear methods } \\
\text { First year university students }\end{array}$ \\
\hline Lehmann (1972) & Ivory coast & Clinical & Interview & BF symptoms & Unclear methods \\
\hline Minde (1974) & Uganda & Clinical & Interview & BF symptoms & $\begin{array}{l}\text { Sample size } \\
\text { Selection bias }\end{array}$ \\
\hline Udofot (1975) & Nigeria & Clinical & $\begin{array}{l}\text { Electrodermal and } \\
\text { electromyography }\end{array}$ & Hyperarousal & Unclear methods \\
\hline Thebaud \& Rigamer (1976) & Liberia & Clinical & Interview & BF symptoms & Unclear methods \\
\hline
\end{tabular}


Table II: Review of BFS Literature between 1980 and 1999

\begin{tabular}{|c|c|c|c|c|c|}
\hline Author (year) & Location & Type of study & Outcome measure & Main Outcome & Methodological problem \\
\hline Morakinyo (1980a) & Nigeria & Clinical & BFSS, EPI, HOQ* & Neuroticism BFS & Choice of tests \\
\hline Morakinyo (1980b) & Nigeria & Clinical & $\begin{array}{l}\text { In-depth exploratory; } \\
\text { drug assisted Interview }\end{array}$ & $\begin{array}{l}\text { Nervous Predisposition } \\
\text { Sleep deprivation } \\
\text { Psychostimulant use in BFS }\end{array}$ & Sample not matched \\
\hline Morakinyo (1985) & Nigeria & Clinical & $\begin{array}{l}\text { Raven's progressive } \\
\text { matrices } \\
\text { Mill-Hill vocabulary scale } \\
\text { William's battery of tests }\end{array}$ & $\begin{array}{l}\text { Paired associate } \\
\text { Learning impaired in BFS }\end{array}$ & $\begin{array}{l}\text { Selection bias } \\
\text { Sample not matched }\end{array}$ \\
\hline Omoluabi (1986) & Nigeria & Clinical & $\begin{array}{l}\text { Psycho physiologic } \\
\text { And psychometric indices }\end{array}$ & $\begin{array}{l}\text { BFS has anxiety and } \\
\text { depressive components }\end{array}$ & $\begin{array}{l}\text { Selection bias } \\
\text { No control for Confounding } \\
\text { diagnosis }\end{array}$ \\
\hline Peltzer and Woldu (1990) & Nigeria & Clinical & $\begin{array}{l}\mathrm{SRQ} \mathrm{a}^{\mathrm{a}} \mathrm{COS}^{\mathrm{b}} \text {, clinical } \\
\text { interview }\end{array}$ & $\begin{array}{l}\text { Sexual identity } \\
\text { Family role function } \\
\text { BF symptoms } \\
\text { Cultural orientation }\end{array}$ & $\begin{array}{l}\text { Sample all females } \\
\text { And no matching }\end{array}$ \\
\hline Guiness (1990b) & South Africa & Survey & $S R Q$, open questions & BF symptoms & Response bias \\
\hline Durst et al (1993) & Israel & Clinical & interview & BF symptoms & Response bias \\
\hline Ensink and Robertson (1996) & South Africa & Survey & $\begin{array}{l}\text { Exploratory model } \\
\text { interview catalogue }\end{array}$ & $\begin{array}{l}\text { Idioms of distress } \\
\text { Including BF symptoms }\end{array}$ & $\begin{array}{l}\text { Translational difficulties; } \\
\text { inter-rater reliability }\end{array}$ \\
\hline $\begin{array}{l}\text { Peltzer, Cherian \& Cherian } \\
\text { (1998) }\end{array}$ & South Africa & Survey & SRQ, COS, SSSc, GSSd & $\begin{array}{l}\text { BF symptoms } \\
\text { Cultural orientation } \\
\text { Collectivism }\end{array}$ & $\begin{array}{l}\text { Results not generalizable } \\
\text { beyond rural pupils }\end{array}$ \\
\hline
\end{tabular}

\section{Table III: Review of BFS Literature as from 2000}

\begin{tabular}{|c|c|c|c|c|c|}
\hline Author (year) & Location & Type of study & Outcome measure & Main Outcome & Methodological Problem \\
\hline Peltzer (2002) & South Africa & Survey & SRQ ${ }^{a}, C^{\prime} S^{b}, S S S^{c}, B F S S$ & BF symptoms & Convenience Sampling \\
\hline Morakinyo and Peltzer (2002) & Nigeria & Survey & $\begin{array}{l}\text { Modified BFSS } \\
\text { Mill-Hill vocabulary scale }\end{array}$ & BFS Proficiency in English & Convenience Sampling \\
\hline Fatoye and Morakinyo (2003) & Nigeria & Survey & BFSS & BFS & $\begin{array}{l}\text { Senior Secondary } \\
\text { Students only }\end{array}$ \\
\hline $\begin{array}{l}\text { Peltzer and Morakinyo } \\
(2003 / 2004)\end{array}$ & Nigeria & Survey & $\mathrm{SRQ}^{\mathrm{a}}, \mathrm{COS}^{\mathrm{b}}, \mathrm{SSS}^{\mathrm{c}}$ & $\begin{array}{l}\text { BF symptoms } \\
\text { Cultural orientation }\end{array}$ & $\begin{array}{l}\text { Small Sample Size; } \\
\text { convenience sampling }\end{array}$ \\
\hline Fatoye (2004) & Nigeria & Survey & BFSS, EPQ, GHQ-30 & $\begin{array}{l}\text { BFS, Neuroticism, } \\
\text { psychomorbidity }\end{array}$ & Samples not matched \\
\hline Ola (2007) & Nigeria & Survey & BFSS & BFS & $\begin{array}{l}\text { Senior Secondary } \\
\text { Students only }\end{array}$ \\
\hline
\end{tabular}


to what extent the participants answered the questionnaires in all the studies, the study by Morakinyo and Peltzer is also limited by the use of a convenience sampling method. ${ }^{12}$

It is essential to distinguish clearly between brain fag symptoms and brain fag syndrome so as to avoid confusion in nosological discussions about BFS and its implications. This will be necessary to elaborate on the culture relatedness of this psychiatric disorder associated. From the review of the literature, patients reported to have BF symptoms were not homogenous in that some of them had other psychiatric diagnoses. One would thus not be surprised if BFS was called an equivalent of either depression or anxiety. Apart from this, in a review of some of the detailed case histories of BFS in non Nigerian/black populations, core symptoms of BFS were lacking using the diagnostic guide of the Brain Fag Syndrome Scale (BFSS).

\section{Correlates of BFS}

It is against the background that BF syndrome has been diluted with BF symptoms that correlates will be discussed.

\section{Gender}

With regard to gender, earlier studies reported that BF was commoner in males. 2,14,15,16,17 One of the reasons attributed to this was that girls with the potential for BF had been taken out of the educational system before getting into secondary schools thus leaving a healthier population of girls than boys in higher institutions. This view has been found to be speculative and the gender difference was more likely to be a reflection of the far larger population of males in higher institutions in all the African countries at their stage of development in 1960s and 1970s. A review of some detailed case histories of $\mathrm{BF}$ among African students in that period revealed that fewer than 5 were females. ${ }^{4,5,18}$ The majority of the studies in the 1990s have not confirmed this gender difference. $7,11,13,19$

\section{Socioeconomic status}

A possible significant association between low socioeconomic status and brain fag had been reported in early studies. ${ }^{2}$ For example, researchers then found a significant relationship between parental literacy (a concept related to SES) and brain fag. However, the response rate of participants to questions eliciting parental literacy was poor in this study. Nonetheless, significant associations between SES and brain fag had been confirmed by later studies which were conducted in South Africa.6,20,21 These authors also found a significant relationship between cultural orientation and BF symptoms. This suggested a putative role of acculturative stress in the development of BF symptoms. However, the study was silent over whether cultural orientation and SES had interactive effects or whether each was independently sufficient to cause brain fag symptoms. In a later study by some of these South African researchers, the rate of BF symptoms was lower than in earlier studies. This would suggest possible reduction in acculturative stress. However, these studies were limited by their sampling technique and use of different sample populations.

\section{Other correlates}

While other risk factors for BFS are shown in Table IV, sociodemographic factors such as age and religion have not been found to be associated with BFS.

Some studies have examined other variables that might be related to BFS. For example, Morakinyo using a psychometric test of cognitive functions, the Progressive Matrices, found that contrary to earlier postulations those with BFS had average or above average intelligence. ${ }^{22}$ This author in another study also found that neuroticism (using the Eysenck Personality Inventory) was high among BFS patients. ${ }^{23}$ This was confirmed by Fatoye in his study among university students in Ile-Ife. ${ }^{7}$ They, however, had greater difficulty learning new English words than those free from the syndrome. ${ }^{12,19}$

Gerald reported a relationship between BFS and isolation from parents, hierarchical barriers in school between teachers and students, communication in second language, greater intergenerational discrepancy in lifestyles, borderline intelligence and faulty study habits. ${ }^{24}$ Ola found that BFS students had 1.2 odds of having poor study habits. ${ }^{13}$ Apart from poor study habits, he also found out that sleep quality and written work were the significant predictors of BFS. Morakinyo found $45.5 \%$ of BFS patients using stimulants, particularly to deprive themselves of sleep, in order to study well into the night. ${ }^{23} \mathrm{His}$ findings have also been replicated. 11,13,25 These factors need to be considered in relation to achievement stress identified by German and Assael in 1971 among Ugandan students. ${ }^{26}$

Omoluabi has investigated the psychophysiological determinants of BFS. ${ }^{27}$ This author found that BFS students had significantly higher scores than the control group in five of the seven psychophysiological measures considered: increases in the muscle tension, heart rate, high systolic and diastolic blood pressures, skin conductance level and lowered peripheral skin temperature. Increases in the muscle tension especially in the frontalis, sternocleidomastoid and trapezius muscles would cause tension headaches while the general increases in sympathetic activity would result in insomnia, poor concentration and memory lapses. This study confirmed the findings of Udofot as well as Awatirife and Kadiri. ${ }^{28,29}$ The sample sizes in these studies were small and their methodologies were not clear.

\section{BFS: a conceptual history}

Owesi Temkin's landmark study on the history of epilepsy, in 1971, marked the emergence of a new trend in the historiography of medicine and would be relevant in this work. ${ }^{30}$ His work is "a model study in the history of disease... not an epidemiological or clinical history of disease but a history of the evolution of ideas

\section{Table IV: Risk factors of Brain Fag Syndrome}

\begin{tabular}{|l|l|}
\hline Risk factors for BFS & Confirmed by other studies \\
\hline $\begin{array}{l}\text { Isolation from parents } \\
\text { Hierarchical barriers in school between } \\
\text { teachers and students }\end{array}$ & NO \\
Communication in second language & NO \\
Greater intergenerational discrepancy & \\
in lifestyles & NO \\
Borderline intelligence & NO \\
Faulty study habits & YES \\
Gender & YES/NO \\
Female birth order & NO \\
Socioeconomic status & YES \\
Cultural orientation & YES \\
Neuroticism & YES \\
Paired associate learning & NO \\
Cognition & YES \\
\hline
\end{tabular}


about epilepsy, its causes, its implications for the lives of sufferers and ideas about its treatment." It is used to a large extent in this work.

The basis of Temkin's approach is to tell a story about a disease organised not just by dates, times, peoples, places, but by the perspectives that have been sought to account for that disease over time. An approach to the history of a disease, through the history of the ideas evoked to explain it, has been called a conceptual history or a historico-intellectual record.

BFS is a history told over time and through space. Divisions into periods and epochs would be arbitrary and would obscure patterns that appear from the historical record. It is only by focusing on the perspectives that such trends become apparent. The conceptual history of BFS can be divided into four major perspectives: Traditional medicine, Psychoanalysis,

Biopsychological and Transcultural psychiatry.

\section{The traditional perspective}

The scope of this paper is the scope of BFS history from its first reference in the Psychological medicine to the most contemporary descriptions in Transcultural psychiatry. While this may seem overly ambitious, the task is narrowed by the sources, limited to academic writings, tertiary references, and personal communications. There is a dearth of studies on how symptoms are labelled and interpreted in cultures where BFS tends to occur

One way to begin studying BFS is to refer to the research literature in anthropology and psychiatry. Jaiyesimi suggested in his paper that there was a need to highlight specific cultural beliefs of indigenous cultures in order to spotlight the credulous background on which concepts of illness thrives. ${ }^{31}$ The salience of BFS, the quickness and extent of its recognition within several cultural groups, is more difficult to establish.

Corin and Murphy wrote that culture-bound syndromes seemed to be less common in Africa than in other parts of the world. ${ }^{32}$ Ityavyar reported that there were very few healers of mental cases and that traditional psychiatry was the least developed in Northern Nigeria where Hausa traditional healers devoted little or no attention to the mentally ill people because they were incurable. ${ }^{33}$ Concerning the authors' catalogue of oral report on culture-bound syndromes in Africa, brain fag was not mentioned.

A review of McCulloch's paper that described the clinical approaches of well-known European psychiatrists who worked directly with indigenous Africans, among them Frantz Fanon, J.C Carothers, and Wulf Sachs, did not reveal idioms of distress identified as components of BFS. ${ }^{34}$ The said European psychiatrists then were a disparate group, operating independently of one another and mostly in intellectual isolation and they shared a coherent set of ideas about The African Mind premised on the colonial notion of African inferiority.

In Csordas and Lewton's survey of literature on religious and spiritual healing on a global scale for the past 20 years, studies were organised by geographical region. ${ }^{35}$ The section on SubSaharan Africa, pp. 470-477, includes short comments on Nigeria (pp. 470-471), quoting five references. 15,36,37,38,39 Mention was not made of brain fag as a category of indigenous distress. It is important to note however that the authors' access to literature on the subject was very limited.

There have been no comprehensive studies focusing specifically on indigenous treatment of the people with neurotic disorders. The attitude of psychiatrists towards indigenous healers and the healers' unwillingness to give information to be used by white people may underlie the fact that there is so little information about treatment of neurotic disorders in indigenous practices, and a large number of practices would have to be surveyed in order to collect such information.

A starting point may be on how indigenous and religious healers conceptualise experiences that within western psychiatric systems would be characterised as broadly neurotic and stress related disorders, including BFS. There is need for descriptions of traditional beliefs and practices around neurotic illnesses. This would provide a basis for subsequent investigations. Ensink and Robertson in their study in 1996 provided a good framework for other researcher's to follow. ${ }^{40}$ They found BF symptoms among idioms of distress among the Xhosa people. More studies are need in this direction since they will probably resolve the controversies on how BFS should be conceptualised. However, earlier methodological problems, including translational difficulties, found in authors who had made anthropological investigations on psychosis such as using problematic and sometimes discriminatory assumptions which reify culture and differences should be avoided. ${ }^{40}$ It has been evident that translation essentially involves a process of interpretation which could alter any syndrome, data set and could affect any subsequent interpretation of the data. Working with translated data makes it more difficult to understand the intention and meaning of responses, as well as their relationship to the data set as a whole.

Anthropological studies on BFS or BF symptoms should also consider other issues such as combined use of quantitative and qualitative methodologies i.e. triangulation, the nature of the informants, and varied expressions of distress locally. This will ensure valid cross-cultural comparison and interpretation of data that will clarify BFS as a distinct nosological entity.

\section{The psychoanalytic perspective}

Since BFS's introduction into the Western literature in 1960, a series of reports attempted psychoanalytic interpretations of the condition. Arguments towards this end were made individually and by far the most cited is Prince.

Prince, in Ego Energy hypothesis, referred to BFS as an ego disease such that the ego had no sufficient energy to cathect the necessary ego apparatus and the external data required in the educational task. ${ }^{41}$ He remarked that the African ego energies habitually employed for high level functions of perception, interest, abstraction or problem solving were not sufficient as in western ego energy that had more than adequate supply of energies for any intellectual task. This lack of energy might result from the tremendous amount of energy required to cope with acculturation and to overcome the cultural discontinuities characterising the shift from the collective and cooperative culture of their childhood to the highly individualistic and competitive requirements of the Western education.

There is some support for the ego energy hypothesis derived from research findings. ${ }^{41}$ Some authors found that the students most prone to BFS were those who came from the least westernised families where acculturation task was most arduous. 2,4,37,42 This might also explain the varying prevalence rates from different countries as the prevalence would vary as the level of westernisation of the culture area from which the students derive. However, this hypothesis does not yield measurable parameters which could be tested.

Another is the Forbidden Knowledge hypothesis. This was first 
proposed by Savage and Prince in 1967. ${ }^{43}$ It holds that the act of study involved the African student is an act of betrayal of his own culture. The degree of betrayal depended on the stage of westernisation of the student's culture - there were 4 stages through which non-western cultures might pass in their disposition towards western education for their children - (i) Opposition wherein western education is rejected so as not to undercut traditional positions of power and control; (ii) Ambivalence wherein some need for western education in some children is seen such that there would be a sort of cultural brokership; (iii) Selective evaluation wherein western education is seen as an important source of prestige and income; and (iv) Projective identification wherein western education is embraced at the detriment of indigenous values. ${ }^{3,44}$ There is an unconscious need in children to please the ancestors because one of the overriding values of African culture is that members should live in accordance with the customs, and behave in a way acceptable to one's family, group and ancestors. ${ }^{43}$ BFS students unconsciously see themselves as betraying their ancestors by reading western books and attending western schools. They suffer BFS as a result. Prince, using Nigeria as a case, proposed that BFS was due to the conflict between the Nigerian personality and its alleged component traits on one hand and the western methods of education on the other hand. ${ }^{41}$ However, there does not seem to be any empirical support for this intuitive theory. ${ }^{23}$ In fact, the studies on personality showed no difference between Nigerians and Europeans. 7,45

Parin carefully describes a case of a young Anyi man from the Ivory Coast whom he effectively treated in eighteen sessions of psychoanalytically oriented psychotherapy. ${ }^{46}$ The author used this case not only to point to the inadequacy of previous attempts to explain this syndrome but also to demonstrate the effectiveness of the psychoanalytic model in understanding and treating this man. In particular, the author contended that a "negative" outcome to the Oedipus complex made this young man vulnerable to neurosis when his encounter with a European-style education led to conflicts.

These hypotheses are results from clinical interviews which have several limitations. First the information gathered during the interview is to some extent preselected by the client. This information may be self-serving. Secondly, some clients are simply unable to provide accurate information in an interview, which might be worse if the interviewer is from a different culture. Thirdly, interviewers may make subjective judgements that skew the information they gather. They usually rely too heavily on first impressions. Their biases may also influence the way they interpret what the patient says. Finally patients respond differently to different interviewers. Hence there is a need to use standardised questionnaires.

\section{The biopsychological perspective}

Morakinyo proposed his psychophysiological theory of BFS after carrying out a clinical investigation of 20 established cases of the syndrome among the students of University of Ife (now Obafemi Awolowo University, lle-Ife). ${ }^{23} \mathrm{He}$ found that BFS sufferers had a very intense drive for achievement and that behind this drive was an anxiety related to the outcome of the educational programme on which the students were engaged. This anxiety made the students adopt a system of study which led to sleep deprivation with use of stimulants to stay awake. The sleep deprivation in turn created an abnormal psychophysiological state in them including cognitive dysfunction. This cognitive dysfunction also constituted a severe threat to their ambition and in turn led to a generation of more tension. A vicious cycle was therefore established which eventually led to BFS. Morakinyo had previously found that BFS patients had higher scores than average on the neuroticismstability dimension of the Eysenck Personality Inventory (EPI) but not different from the average on the Extraversion-Introversion dimension. He therefore concluded that BFS was the consequence of interplay of psychological and physiological factors in persons of nervous predisposition. The physiological factors identified included sleep deprivation and psychostimulant use while the psychological factors included achievement motivation. Specially designed tests for these factors identified are lacking. Studies need to be undertaken to test this hypothesis.

Omoluabi has investigated the psychophysiological determinants of BFS by relating it to test anxiety, because both were associated with studying and that the psychophysiological indices of BFS could be inferred from an analysis of the physiological determinants of test anxiety. ${ }^{27}$ He proposed that there was a physiological hyperarousal in BFS sufferers that resulted from the mediation by the cortex of a cognitive response to a stressor (studying)

The cognitive appraisal of the stressor was transmitted to the hypothalamus which would prepare the body to cope with the effects of the stressor through two pathways: the hypothalamopituitary-adrenal axis and the sympathetic division of the autonomic nervous system (ANS). The appraisal through the ANS pathway resulted into increases in the muscle tension, heart rate, skin conductance level and lowered peripheral skin temperature. Increases in the muscle tension especially in the frontalis, sternocleidomastoid and trapezius muscles would cause tension headaches while the general increases the sympathetic activity would result in insomnia, poor concentration and memory lapses.

This author also found that BFS subjects responded to examination stress by worrying (on Test Anxiety Inventory -TAI worrying score) unlike the control subjects who responded to examination stress by being emotional (on TAI emotionality score). Worrying during the test situation had earlier been found to be more detrimental to academic performance than emotionality. ${ }^{47}$ The BFS students saw examinations and the consequences of the examinations as ego threatening according to Omoluabi and he therefore saw the stressor triggering the BFS as examination stress. ${ }^{27}$

\section{Intervention studies}

These are limited to clinical studies conducted among BFS sufferers, but with unclear methodologies

Anumonye reported that sixty male Nigerian students suffering from 'brain fag' syndrome who had failed to respond satisfactorily to 4 to 8 weeks' treatment with other benzodiazepines were treated with 1 to $2 \mathrm{mg}$. lorazepam t.i.d. ${ }^{48}$ There was marked improvement in symptoms in over $80 \%$ of the patients by the end of the second week of lorazepam treatment. Side-effects were considerably less frequent or incapacitating than with the previous therapy.

Morakinyo reported that in managing BFS the history taking and the mental state examination of the patient must establish the presence of the four components of the syndrome before a definitive diagnosis could be made. ${ }^{49}$ This together with the use of stimulants to keep awake to study, particularly as examinations approach. A study in East Africa showed that BFS sufferers 
benefited from muscular relaxation exercises. Other studies have shown that some patients were relieved when given antidepressant drugs. These two effective remedies must be due to their reduction of the fourth of the four components of the syndrome listed above i.e. affective reactions to the difficulty with study. However, counselling which is aimed at improving the sleep hygiene and study habit of the patient can be very effective. The use of Anxiolytics should be minimised.

\section{Transcultural Perspective}

BFS is cultural related, specific syndrome. This is because it is a collection of symptoms and signs that is restricted to a limited number of cultures primarily by reason of certain of their psychosocial features. The cultural influence on this syndrome could be said to occur in at least five ways using the model explanation of Tseng. ${ }^{50}$ There is the cultural influence on the formation of this disorder - pathogenic effect. The cultures in which it is found have selected coping patterns to deal with the stress of studying - psychoselective effect. The clinical manifestation of the syndrome is modified to a great extent by the cultures - psychoplastic effect. There are evidences supporting the cultural promotion of the frequency of its occurrence psychofacilitating effect. And the possibility of these specific cultures shaping the folk responses to it cannot be excluded psychoreactive effect.

Understanding these effects is necessary to understand the nature of this culture related disorder in an appropriate and meaningful way. This understanding is revealed in the construction of the 7 item Brain Fag Syndrome Scale (BFSS) in 1990.49 With BFS delineated as a distinct nosological entity, Prince and Morakinyo refined the questionnaire with an aim to shed more light on the nature, prevalence and factors associated with the syndrome in a comparative study of school children in Canada and Nigeria.

In the light of what is said above, the discussion of the elaboration of BFS over the years will be better understood. In 1963, Prince identified the syndrome as a very common psychiatric disorder. ${ }^{51}$ Patients were mostly in secondary school or university or teachers or government clerks who were studying in their spare time to raise their educational levels. These patients generally attributed their illnesses to the fatigue of the brain due to excessive mental work

Prince noted that, in Nigeria, education was often a family affair in which one of the higher children was supported financially by family members and the educated member, in turn was expected to be responsible for the other family members when the need arose. This family aspect of education burdened the student with the responsibility of maintaining the family prestige. Thus, his or her academic success or failure was associated with great stress.

Two decades later, a psychiatrist from Nigeria, R. O. Jegede, observed that the disorder was found in people other than students and that excessive studying for examinations was just one of the several possible precipitating factors. ${ }^{52}$

A quarter of a century after he first described the disorder among the major/other ethnic groups in Nigeria, Prince and Peltzer wrote that it was commonly found in Uganda, Liberia, Ivory Coast (Cote d'Voire) and Malawi. ${ }^{38,53}$ This confirmed that BFS was widespread and prevalent among students in sub-Saharan Africa.

However, since its discovery, the BFS has been a controversial issue in its status as a distinct nosological entity. Neki and Marinho classified it as either a depressive reaction or an anxiety state manifesting in somatised form. ${ }^{15}$ Anumonye viewed it as a mood disorder, and Prince and Jegede saw it as a depressive equivalent. $38,52,54$ Guinness argued that it was a form of anxiety disorder, while Peltzer, Cherian and Cherian argued that it might be an anxiety-depression equivalent. $6,55 \mathrm{Mbanefo}$, Ayonrinde, Ebigbo and Thezue, Ezeilo and Nwezie, saw BFS as somatisation. $56,57,58,59,60$

The divergence of opinions might result from the use of inappropriate assessment instruments - the Brief Psychiatric Rating Scale, Zung's Depression Scale, Hamilton's Anxiety Checklist, Psychosocial Stress Scale, and the Enugu Somatisation Scale. ${ }^{27,61}$ Omoluabi thus remarked about the number of conceptual and methodological shortcomings that were inherent in the above studies and said BFS could be a distinct nosological entity. ${ }^{27}$ The confusion about the nosological status of the BFS seems to result mainly from speculative opinions, failure to define the syndrome properly by authors, lack of biological markers to complement the clinical phenotype of the condition and the fact that most studies did not use the BFSS which is based on the definition of the syndrome.

In 2003, Fatoye and Morakinyo described BFS as a distinct nosological entity but which shares features with somatisation, obsessive compulsive and depressive disorders. ${ }^{11}$ A study by Okulate, Olayinka and Jones confirmed this. ${ }^{61}$ These authors aimed to determine what weight should be assigned somatic symptoms concerning depression and other mental disorders in African countries such as Nigeria. They recruited 829 persons to complete the Patient's Health Questionnaire (PHQ). Using principal component analysis and a logistic regression model, they found five factor loadings. Factor One was labelled "core depressive symptoms" and was found to account for $26.4 \%$ of the variance of depression. Factors Two to Five were labelled "head somatisation", "body somatisation", "brain fag syndrome" and "somatic anxiety". They found that somatic symptoms loaded separately from the core depressive symptoms and were not good predictors of depression. Using a logistic regression model with depression in two categories (depression or otherwise) as the outcome variable, and entering all the somatic and depressive symptoms as independent variables, they found only core depressive symptoms and back pain to have odds ratios that were statistically significant to predict depression. The cognitive factor (difficulty in concentrating) loaded to the BFS factor. These authors therefore concluded that psychological symptoms were necessary in the diagnosis of depression and that somatic symptoms as well as cognitive ones were required to make the diagnosis of the BFS.

\section{Future directions}

How could the controversy that BFS is not different from either depression or anxiety be solved? Though the proponents of equivalent view maintain that two persons with a diagnosis of depression can present entirely different patterns of symptoms especially if they are from different cultures, we also see no reason why one person cannot satisfy the criteria for both depression and BFS (co-morbidity) just like there is no a priori reason why a person cannot suffer both cancer and a heart disease. We therefore propose that studies using multivariate techniques i.e. factor analysis or cluster analysis on psychopathological data be done to see if BFS will appear in one of the factors or clusters. Possible correlations or co-occurrences that may appear may require the revision of the BFS diagnostic criteria. 
Moreover, rather than using a prototypical or exemplar based view which have been widely criticised because of their demerits in DSM nosology, modularity framework of the brain may be found useful. In this framework, the brain is conceived as a system of mental modules or faculties analogous to various organs in the body. In the same way that the stomach functions to digest food, each of the mental modules (organs) is specially geared to perform a particular mental task such as cognition, emotion and motivation. Hilgard referred to these mental organs as the fundamental and irreducible faculties of the brain. ${ }^{62}$ In BFS, any of these modules or connections among them can be damaged resulting in particular patterns of psychological deficits. For instance, Morakinyo found a deficit in paired associative learning among BFS sufferers. This suggests a problem in the cognitive module. ${ }^{22}$ The anxious or depressive symptoms in BFS patients would suggest problems with the emotional organ or a connectivity problem between emotion, cognition and motivation given the empirical data that BFS persons have high ambitions or are determined to succeed in studying. Hence we propose that specially designed tests for differential psychological deficits on BFS/depressive patients be undertaken.

It is also desirable to carry out intensive clinical evaluations of individual cases from a cultural perspective rather than focus only on clinical manifestations of BFS. There is a need to understand the BFS sufferer's personal history including family background, psychological development, encountered stresses and coping patterns. Any cultural belief that may be related to stresses encountered or coping mechanisms used will need elaboration so that underlying cultural attributes can be revealed.

Beyond these intensive clinical evaluations of individuals, the total geopolitical/ideological and socioeconomic circumstances of the societies in which BFS occurs or tends to occur need to be examined. This will require the study of how symptoms are labelled in these societies and how the symptoms are interpreted across these societies which differ in structure and culture. The use of culturally appropriate measurement methods that include a broad range of indigenous symptoms and signs that can be reliably assessed will be required. Ensink and Robertson's study in 1996 among South African Xhosa children and adolescents which revealed indigenous categories of brain fag is relevant. ${ }^{40}$ More similar works are required in different cultures where BFS tends to occur. The relevant ethnographic and anthropological data gathered will reveal what constitutes BF symptoms and particularly BF syndrome. A more meaningful understanding of the metamorphosis of BFS will be revealed against the background of shift in the circumstances of these societies. This will highlight how individuals respond to culture related stresses with culture conditioned reactions within a particular sociocultural climate.

In order to reveal further the influence of sociocultural factors, examinations of the variations in the incidence and age corrected morbidity risk of BFS across different populations/settings are warranted. To date, only one study had examined the prevalence of BF symptoms in different settings. ${ }^{55}$ Prospective studies are also needed to assess BF symptoms and BFS patient's perceived cause of the illness. This will reveal how patients' explanatory models relate to BFS diagnosis and how they may predict the course of BFS.

Surveys of non patient populations in BFS prevalent societies and comparison of their responses with individuals in communities where BFS seldom occurs will further reveal the actual contributions of cultural factors to BFS. So will the comparison of BFS patients from different cultures who are similar in age, social class, religion and other relevant sociocultural variables.

\section{Conclusion}

The conceptual history has been able to address its existence, its form and structure, what should be classified, how and ways of classification. From its conceptual history, BFS as a phenomenon, with its distinct presentations, is subjectively real and is best classified with the framework of psychiatry, psychology and or sociology. However, its course, response to treatment and outcome deserve more attention than has been given.

\section{Acknowledgement}

We wish to acknowledge the permission given by the Royal College of Psychiatrists to reproduce the prototype case history in the text without breaching their rules.

\section{References}

1. American Psychiatric Association Diagnostic and Statistical Manual of Mental Disorders, 4th Edition. Washington, DC. 1994.

2. Prince RH. The Brain Fag syndrome in Nigerians students, Journal of Ment. Sc. 1960; 106: 559-570.

3. Wintrob RM. The cultural dynamics of student anxiety: A report from Liberia. In Boroffka A, eds, Report on Seminar/Workshop on Psychiatry and Mental Health Care in General Practice. Ibadan, 1971.

4. Lehmann JP. Le vecu corporel et ses interpretations en pathologie africaine a propos des inhibitions intellectuelles en milieu scolaire, (The somatic sensations and their interpretation in regard of African pathology; considering the intellectual inhibitions in school), Rev. Med. Psychosom. Psychol. Med. 1972; 1, 43-67.

5. Thebaud E, Rigamer EF. Some considerations on student mental health in Liberia, African Journal of Psychiatry 1976; 1: 227-232.

6. Peltzer K, Cherian VI, Cherian L. Brain fag symptoms in rural South African secondary school pupils, Psychological Reports 1998; 83: 1187 1196.

7. Fatoye FO. Brain fag syndrome among Nigerian undergraduates: present status and association with personality and psychosocial factors. Ife Psychologia 2004; 12 (1), 74-85.

8. Prince RH. Functional symptoms associated with study among Nigerian students. West African Medical Journal 1962; 11: 198-206.

9. Durst R, Minuchin-Itzigsohn S. et al. "Brain-fag syndrome: manifestation of transculturation in an Ethiopian Jewish immigrant." Israel Journal of Psychiatry and Related Sciences 1993; 30(4): 223-232.

10. Peltzer K, Woldu S. (1990). The brain fag syndrome in female Nigerian students: intercultural analysis and intervention of gender change. Curare 1990; 13: 141-146.

11. Fatoye FO, Morakinyo O. Study difficulty and the 'Brain Fag' syndrome in south western Nigeria. Journal of Psychology in Africa 2003; 13, 70-80.

12. Morakinyo O, Peltzer K. Brain Fag symptoms in apprentices in Nigeria, Psychopathology 2002; 35: 362-366.

13. Ola BA. Dissertation: Study habits, sleep patterns and the "Brain Fag Syndrome" among secondary school students in Ile-Ife, Osun State, Nigeria. 2007.

14. Boroffka A, Marinho A. Psychoneurotic syndromes in urbanized Nigerians. Transcultural Psychiatric Research Review 1963; 15: 44-46.

15. Neki JS, Marinho AA. A reappraisal of the "Brain Fag" syndrome. A paper presented at the 2nd Pan-African Psychiatric Conference, March 1968, Dakar, Senegal. 
16. German GA, Arya OP. Psychiatric morbidity amongst a Ugandan population. British Journal of Psychiatry 1969; 115: 1323-1329.

17. German GA, Assael K, Muhangi J. Psychiatric disorders associated with the mid-adolescent years. In Proceedings of the Second Pan-African Psychiatric Workshop, 1970: 131-135, Mauritius.

18. Chakraborty A, Mallick A. Headache (a cross-cultural study). Indian Journal of Psychiatry 1966; 8 (2): 101-108.

19. Peltzer K, Morakinyo O. Brain fag syndrome in Nigerian university students of languages and medicine. Psychopathologie Africaine 2003/2004; 32 (2): 201-211.

20. Guinness EA. Profile and prevalence of the brain fag syndrome: psychiatric morbidity in school populations in Africa. British Journal of Psychiatry 1992a; 160, 42-52.

21. Peltzer K. Brain fag symptoms among black South African university students, Southern African Journal of Child and Adolescent Mental Health 2002; 14 (2): 115-122.

22. Morakinyo O. The Brain Fag Syndrome in Nigeria: cognitive deficits in an illness associated with study. British Journal of Psychiatry 1985; 146: 209210 .

23. Morakinyo O. A psycho-physiological theory of a psychiatric illness (the Brain Fag syndrome) associated with study among Africans, Journal of Nervous and Mental Disease 1980a; 168 (2): 88-89

24. Gerald K. An attempt to estimate the incidence of mental disturbances among students. In Student Mental Health in Africa: present status and future prospects. 15th annual lecture of the West Africa College of Physicians, 1970, Accra, Ghana.

25. Eegunranti AB. Dissertation: Stimulant Use and psychopathology among secondary school students in Osogbo, Osun State, Nigeria. 2006.

26. German GA, Assael MI. Achievement stress and psychiatric disorders amongst students in Uganda. Israel Annals of Psychiatry and Related Disciplines 1971; 9: 30-38.

27. Omoluabi PF. Psychophysiological indicants of brain fag syndrome. In Wilson EB, eds, Psychology and Society. Osogbo: Igbalaiye, 1986: 112119 .

28. Udofot SU. Dissertation: Skin conductance measurements and electromyographic activity in Nigerian university students with the "Brain-Fag"syndrome, Ile-Ife, 1975.

29. Awaritefe A, Kadiri AV. Validation of the STAI in Nigerian subjects. IRCS Medical Sciences: Psychology and Psychiatry; Social and Occupational Medicine 1981; 9, 419-420.

30. Temkin O. The falling sickness: A history of epilepsy from the Greeks to the beginning of modern neurology. 2nd Edition: Baltimore, 1971: 467.

31. Jaiyesimi F."Elere": a critical evaluation of its psychology. Dokita (Ibadan) 1967; 9, 7-11.

32. Corin E, Murphy, HB. Psychiatric perspectives in Africa. Part I: The Western viewpoint. Transcultural Psychiatric Research Review 1979; 16, 147-178.

33. Ityavyar DA. (1981). Culture and health in Hausa Land. University of Jos. Media Magazine in Nigerian Sunday Standard. Oct.4. 1981.

34. McCulloch J. Colonial Psychiatry and the "African Mind". Cambridge: Cambridge University Press. 1995.

35. Csordas TJ, Lewton E. Practice, performance, and experience in ritual healing. Transcultural Psychiatry 1998; 35, 435-512.

36. Awanbor D. The healing process in African psychotherapy. American Journal of Psychotherapy 1982; 36, 206-213.

37. Prince RH. The changing picture of depressive syndromes in Africa: is it fact or diagnostic fashion? Canadian Journal of African Studies 1968; 1: 177-192.

38. Prince RH. Some transcultural aspects of affective disorders in adolescents: the example of the brain fag syndrome in African students In: Golombek H, Garfinkel BD, eds, The Adolescent and Mood
Disturbance. New York: International University Press, 1983: 53-71.

39. Wall L. Hausa Medicine: Illness and Well-Being in a West African Culture. Durham, NC, Duke University Press, 1988.

40. Ensink K, Robertson B. Indigenous categories of distress and dysfunction in South African Xhosa children and adolescents as described by indigenous healers. Transcultural Psychiatric Research Review 1996; 33, 137-171.

41. Prince RH. (1979). The brain-fag syndrome. In Peltzer K, Ebigbo PO, eds., A Textbook of Clinical Psychiatry in Africa. Enugu: Chuka, 1979: 276287

42. Minde K. Study problems in Ugandan students. British Journal of Psychiatry 1974; 125: 131-137.

43. Savage C, Prince RH. Depression among the Yoruba. In: Muensterberger W. Axelrad S, 4th Edition, The Psychoanalytic Study of Society 1967: 8398

44. Wintrob RM. Rapid socio-cultural change and student mental health, two sections, McGill Journal of Education, 1969, 1970; 4: 174-183 and 5: 5664.

45. Morakinyo O. Personality variables in psychiatric illness associated with study among Africans. African Journal of Psychiatry 1980b; 6: 1-5.

46. Parin P. A Case of "Brain-Fag" Syndrome: Psychotherapy of the Patient Adou A. in the Village of Yosso, Ivory Coast Republic, Psychoanalysis Quarterly 1984; 55:197-197.

47. Spielberger CD. Understanding stress and anxiety. London: Harper and Row publishers, 1969.

48. Anumonye A. Treatment of 'brain fag'syndrome. Curr Med Res Opin. 1975; 3 (6): 367-70

49. Morakinyo O. Student mental health in Africa: present status and future prospects. 15th Annual lecture of the West African College of Physicians, 1990, Accra, Ghana.

50. Tseng WS. Handbook of Cultural Psychiatry. San Diego, CA: Academic Press, 2001.

51. Prince RH. The concept of culture bound syndromes; anorexia nervosa and brain fag. Transcultural Psychiatric Research Review 1985; 22: 117121 .

52. Jegede RO. Psychiatric illness in African students: "Brain fag" syndrome revisited. Canadian Journal of Psychiatry 1983; 28, 188-192.

53. Peltzer K. Traditional healing and psychosocial health care in Malawi. Heidelberg: Asanger, 1987

54. Anumonye A. Brain Fag Syndrome. Lausanne: International Council on Alcohol and Addictions. 1983

55. Guinness EA. Social origins of the brain fag syndrome. British Journal of Psychiatry 1992b; 160 (suppl. 16), 53-64

56. Mbanefo SE. Heat in the body as a psychiatric symptom. African Journal of Psychiatry 1966; 1, 2, 131-137.

57. Ayorinde A. Heat in the head: A semantic confusion. African Journal of Psychiatry 1977; 1, (2), 59-63

58. Ebigbo PO, Ihezue UH. Psychosomatic observation as the symptoms of "Heat in the Head". African Journal of Psychiatry 1981; 1 \& 2, 25-30

59. Ezeilo BN. Somatisation of psychological distress among Nigerian undergraduate medical outpatients. Psychopathologie Africaine 1982; XVIII, 3, 363-372.

60. Nwezie L. Emotional stress and psychoneurotic symptom expression among undergraduate students. Paper presented at the 4th Annual Conference of the Nigerian Association of Clinical Psychologists, 1984b, Jos, Nigeria.

61. Okulate GT, Olayinka MO, Jones OBE. Somatic symptoms in depression: evaluation of their diagnostic weight in an African setting. British Journal of Psychiatry 2004; 184: 422-427.

62. Hilgard ER. The trilogy of mind: Cognition, affection, and conation. Journal of the History of the Behavioural Sciences 1980; 16, 107-117. 